\title{
Recurrent debilitating calf pain associated with fasciitis in Familial Mediterranean fever and response to canacinumab
}

\author{
Belde Kasap Demir ${ }^{1,2 \odot}$, Demet Alaygut ${ }^{2 \oplus}$, Caner Alparslan ${ }^{2 \oplus}$, Eren Soyaltın ${ }^{2 \oplus}$, \\ Fatma Mutlubaş ${ }^{2 \oplus}$, Seçil Arslansoyu Çamlar ${ }^{2 \oplus}$, Önder Yavaşcan ${ }^{2 \odot}$ \\ ${ }^{1}$ Division of Nephrology and Rheumatology, Department of Pediatrics, İzmir Katip Çelebi University, İmir, ${ }^{2}$ Division of Nephrology, \\ Department of Pediatrics, Health Sciences University, İzmir Tepecik Training and Research Hospital, Izmir, Turkey.
}

\begin{abstract}
Background. Myalgia is one of the presenting symptoms of Familial Mediterranean Fever (FMF), which is reported at a rate of $27-39.6 \%$. Recurrent fasciitis in those cases are extremely rare. We aimed to present a case with FMF having radiologically proven fasciitis.

Case. An 11-year-old male patient with a diagnosis of FMF and M694V homozygote mutation, using colchicine regularly at a dose of $2 \mathrm{mg} /$ day $(0.08 \mathrm{mg} / \mathrm{kg} /$ day $)$ for 4 years; was admitted to the hospital with severe pain and tenderness on the right calf. There were no accompanying symptoms like fever or abdominal pain. He described three similar episodes with pain and tenderness in left and right calves, which were not accompanied by fever in the last 6 months. The erythrocyte sedimentation rate and C-reactive protein levels were high and serum creatinine kinase was normal. The day after initiation of non-steroidal anti-inflammatory drug (NSAID), his complaints regressed. However, after a week, he again had a severe calf pain. Lower extremity arterial and venous doppler ultrasonography was normal. Increased peripheral signal intensity and fasciitis around the soleus muscle was defined in MRI. With NSAIDs, myalgia disappeared in a few days and acute phase reactants decreased within a week. In the follow up, canakinumab was prescribed due to febrile attacks as frequent as once a month and calf pain observed almost weekly. Thereafter, both febrile attacks and recurrent debilitating calf pain were completely ceased.
\end{abstract}

Conclusion. There are three cases in the literature with fasciitis related myalgia. With this case, we wanted to emphasize fasciitis as a cause of FMF associated myalgia on MRI. In such cases MRI may be helpful to demonstrate fascial involvement.

Key words: Familial Mediaterranean Fever, fasciitis.

Familial Mediterranean Fever (FMF) is the most common monogenic auto-inflammatory disease in the world due to autosomal recessive mutation in MEFV gene located on the short arm of chromosome 16. Myalgia is defined as pain and/or tenderness in the extremities in the absence of joint swelling or signs of underlying osteomyelitis. ${ }^{1}$ It is a well-known clinical

$凶$ Belde Kasap Demir

beldekasap@gmail.com

Received 13th March 2019, revised 9th July 2019, accepted 8th September 2019.

This study was presented at the 51th Anniversary Meeting of the European Society for Paediatric Nephrology 3-6

October 2018, Antalya, Turkey. manifestation of FMF, but it is not as common as arthralgia, fever, abdominal or chest pain. When directed questions are used, myalgia may be detected in up to $20-25 \%$ of the patients with FMF. ${ }^{1,2}$

There are four known patterns of myalgia associated with FMF: Spontaneous myalgia, exercise-induced myalgia, protracted febrile myalgia and colchicine-induced neuromyopathy. ${ }^{1-4}$ Not all the patients with myalgia are evaluated with MRI or muscle biopsy. However, in some cases, fasciitis may be the underlying cause when evaluated radiographically. Furthermore, recurrent fasciitis in cases with FMF is extremely rarely 
described. Herein, we aimed to present a child with FMF who was radiologically diagnosed with fasciitis and reviewed the literature for previously reported cases with FMF and fasciitis.

\section{Case Report}

An 11-year-old male patient with a diagnosis of FMF and M694V homozygous mutation, using colchicine regularly at a dose of $2 \mathrm{mg} /$ day $(0.08 \mathrm{mg} / \mathrm{kg} /$ day) for 4 years was admitted with a debilitating pain and tenderness on the right calf leading him to use wheel chair. He denied any accompanying symptom like fever or abdominal pain. He described three similar episodes of pain and tenderness in his both calves, which were not accompanied by fever in the last 6 months. Tenderness was assessed with palpation on the right calf on physical examination. The laboratory findings were as follows; erythrocyte sedimentation rate (ESR): $44 \mathrm{~mm} / \mathrm{h}$ (N: 0-20), C-reactive protein (CRP): 48.5 mg/L (N: 0-5), leukocytes: 9500 U/L (N: 450015000) (22.6\% lymphocyte, $69.4 \%$ leukocyte), creatinine $0.6 \mathrm{mg} / \mathrm{dl}$ ( $\mathrm{N} 0.5-1.2)$, sodium 139 $\mathrm{mmol} / \mathrm{L}(\mathrm{N} \mathrm{134-150)}$, potassium: $3.74 \mathrm{mmol} / \mathrm{L}$ (N: 3.5-5.5), calcium: $9.8 \mathrm{mg} / \mathrm{dl}(\mathrm{N}: 8.8-10.8)$, phosphorus: $4.8 \mathrm{mg} / \mathrm{dl}(\mathrm{N}: 4-7)$, magnesium: $2.5 \mathrm{mg} / \mathrm{dl}$, total protein: $8.2 \mathrm{~g} / \mathrm{dl}(\mathrm{N}: 5.7-8.0)$, albumin: $4 \mathrm{~g} / \mathrm{dl}$ (N: 3.5-5.2), creatinine kinase: $150 \mathrm{mg} / \mathrm{dl}$ (N: 0-171), lactate dehydrogenase: $207 \mathrm{U} / \mathrm{L}$ (N: 110-295), AST: $32 \mathrm{U} / \mathrm{L}$ (N:0-50), ALT: $20 \mathrm{U} / \mathrm{L}$ (N:0-50).

The day after initiation of non-steroidal antiinflammatory drug (NSAID), his complaints regressed. In the control of acute phase reactants, CRP decreased to $11.7 \mathrm{mg} / \mathrm{L}$ (N: 0-5) and ESR decreased to $31 \mathrm{~mm} / \mathrm{h}$. However, after a week, he had a calf pain again. There were no pathological findings in lower extremity arterial or venous doppler ultrasonography. A thin fluid accumulation and a slight increase in peripheral signal intensity were detected in the soleus muscle in magnetic resonance imaging (MR) and was compatible with fasciitis (Figs. 1 and 2). Right lower extremity electromyography for muscle involvement was normal. The patient continued on non-steroidal anti-inflammatory therapy and colchicine dosage ( $2 \mathrm{mg} /$ day) was not changed. Myalgia disappeared within a week. In the follow-up period, the patient had attacks of abdominal pain, fever, arthritis at least once a month and leg pain in both calves as frequent as once a week. As he had been accepted as resistant to colchicine, canakinumab was instituted. Since then, he neither had isolated

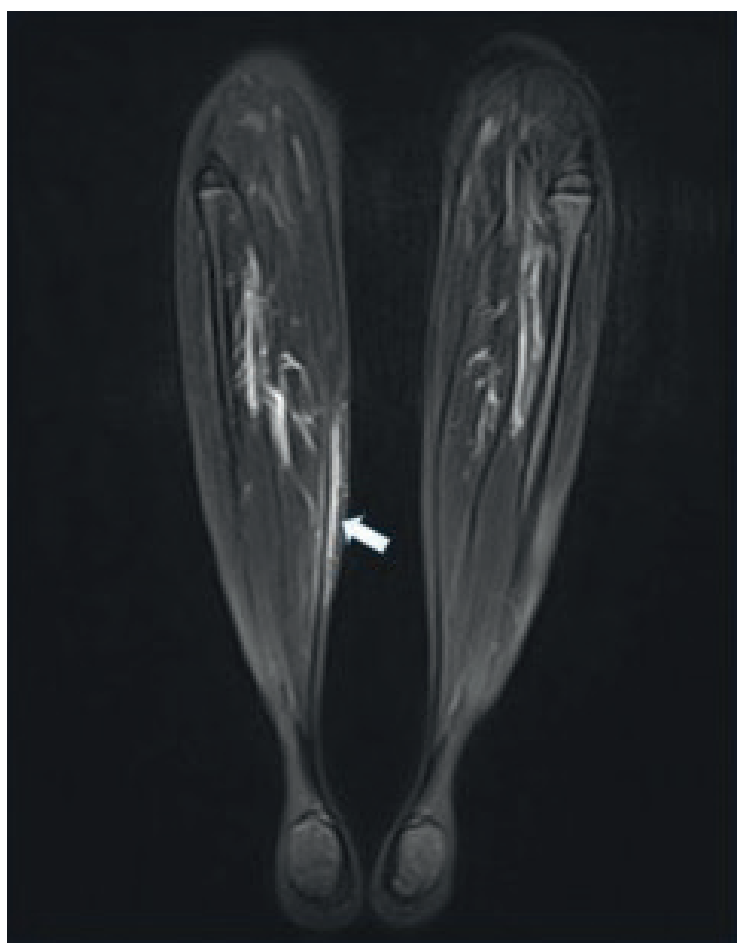

Fig. 1. A thin fluid accumulation along with the fascia of the soleus and a slight increase in peripheral signal intensity in the coronal sections of magnetic resonance imaging (MRI) (white arrow).

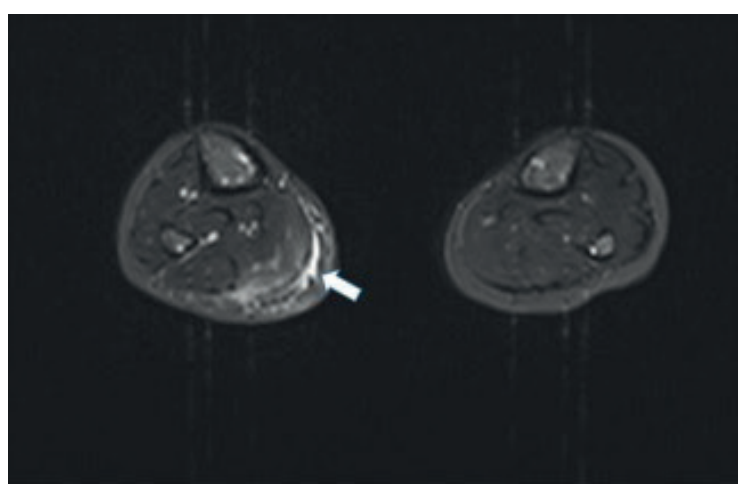

Fig. 2. The same findings in the tansverse sections of MRI (white arrow). 
leg pain due to fasciitis nor any febrile attacks of FMF. An informed consent was received from the family.

\section{Discussion}

Fasciitis in autoimmune or auto inflammatory diseases have been reported in several cases. It is mostly seen in patients with tumor necrosis factor receptor-associated periodic syndrome (TRAPS) ${ }^{5,6}$ In addition, patients with psoriatic arthritis, polyarteritis nodosa, eosinophilic fasciitis and inflammatory myopathy with abundant macrophages may have fasciitis. ${ }^{4,7}$ In FMF, fasciitis has rarely been reported in a few cases, although myalgia is a well-known clinical component.

Abnormal muscular patterns in FMF are spontaneous myalgia, exercise-induced myalgia, protracted febrile myalgia syndrome (PFMS) and colchicine-induced neuromyopathy. ${ }^{2,4}$ Spontaneous myalgia is defined as febrile myalgia not related to exercise or any other precipitating factor, which lasts for about 8 hours to 1 day. Fever is low grade and pain is mild to moderate. Exertional myalgia is the most common form, which lasts from hours to a few days, subsides with rest and occurs without fever or elevated levels of acute phase reactants. ${ }^{1-4}$ The most severe form is PFMS, which is usually symmetrical lasting more than 5 days with normal muscle enzyme levels and elevated levels of inflammation markers (ESR $80 \mathrm{~mm} / \mathrm{h}, \mathrm{CRP} \geq 5 \mathrm{mg} / \mathrm{dl}$ ) in an FMF patient with fever $\left(\geq 38^{\circ} \mathrm{C}\right)$ and at least M694V mutation in one allele. Muscle biopsy and electromyography (EMG) findings are usually normal. Response to NSAIDs or spontaneous recovery is unlikely, whereas a dramatic response to steroids is typical. ${ }^{8}$ Colchicine-induced myopathy is characterized by proximal muscle weakness mostly without pain in the presence of peripheral neuropathy, elevated muscle enzymes leading to rhabdomyolysis, and myopathic changes and axonal polyneuropathy on EMG. Lysosomal vacuolar changes without inflammatory cell infiltration are observed in muscle cells. ${ }^{9}$
Patients diagnosed with FMF and recurrent calf pain have been reported ${ }^{10}$, however, not all the patients with myalgia are evaluated with MRI or muscle biopsy on every occasion. There have been 3 previously reported cases with fasciitis and FMF (Table I).

Kotevoglu et al. ${ }^{12}$ reported a 13-year-old girl with FMF presenting with fever and muscle pain in her right leg and knee. The patient had two similar episodes of muscle pain and maintained complete recovery after steroid treatment. MRI revealed non-specific edema of the subcutaneous fat tissue and increased signal intensity of the intermuscular septa and the distal lateral part of the medial gastrocnemius muscle. In addition, biopsy of the cutaneous and subcutaneous tissue with the fascia of the muscle revealed inflammatory infiltration with leukocytes, lymphocytes and eosinophils consistent with fasciitis. Although the patient maintained complete recovery after steroid treatment on the previous two episodes, she did not need steroids for the last attack as her symptoms resolved spontaneously. Her medical history was remarkable for attacks of abdominal pain and fever. She was found to have MEFV gene mutations and was diagnosed with FMF. She began to receive colchicine thereafter and suffered no attacks during the following two years. Muscle pain in her legs was thought to be associated with PFMS.

Fujikawa et al. ${ }^{4}$ reported a 22-year-old Japanese man with fever and prolonged severe myalgia of the upper and lower extremities lasting for 3 weeks accompanied by elevated CRP and normal CK levels, suggestive of PFMS. Thickening of the fascia was observed on MRI. He responded quickly to prednisolone. Upon his medical history of recurrent fever, arthralgia, erythema, headaches, chest pain starting at 10 years of age and family history including a sister diagnosed with FMF, colchicine was instituted with the diagnosis of FMF. Genetic analysis revealed mutations in MEFV gene.

Umeda et al. ${ }^{13}$ reported fasciitis in a 64-yearold Japanese woman. She had recurrent fever 
Table I. Characteristics of patients with FMF and fasciitis.

\begin{tabular}{|c|c|c|c|c|}
\hline & $\begin{array}{c}\text { Case } 1 \\
(\text { Ref no } 11)\end{array}$ & $\begin{array}{c}\text { Case } 3 \\
\text { (Ref no 4) }\end{array}$ & $\begin{array}{c}\text { Case } 2 \\
\text { (Ref no 12) }\end{array}$ & Our case \\
\hline Age & 13 & 22 & 64 & 11 \\
\hline Gender & $\mathrm{F}$ & M & $\mathrm{F}$ & M \\
\hline Nationality & Turkish & Japanese & Japanese & Turkish \\
\hline Fever & $(+)$ & $(+)$ & $(+)$ & $(-)$ \\
\hline CRP/ESR & $\uparrow$ & $\uparrow$ & $\uparrow$ & $\uparrow$ \\
\hline CPK & $\mathrm{N}$ & $\mathrm{N}$ & $\mathrm{N}$ & $\mathrm{N}$ \\
\hline $\begin{array}{l}\text { Localization of } \\
\text { myalgia }\end{array}$ & Right calf & $\begin{array}{l}\text { Upper and lower } \\
\text { extremities }\end{array}$ & Left thigh & Left and right calves \\
\hline Muscle biopsy & $\begin{array}{l}\text { Leukocyte, lymphocyte and } \\
\text { eosinophil infiltration }\end{array}$ & ND & $\begin{array}{l}\text { Neutophilic } \\
\text { infiltration both into } \\
\text { the fascia and vacular } \\
\text { endothelium of the } \\
\text { fascia }\end{array}$ & ND \\
\hline MRI findings & $\begin{array}{l}\text { Diffuse edema of the } \\
\text { subcutaneous fat tissue, } \\
\text { increased signal intensity } \\
\text { of the intermuscular septa } \\
\text { and distal lateral part of the } \\
\text { medial gastrocnemius muscle }\end{array}$ & $\begin{array}{l}\text { Thickening of the } \\
\text { fascia }\end{array}$ & $\begin{array}{l}\text { High intensity in } \\
\text { femoral muscle and } \\
\text { fascia }\end{array}$ & $\begin{array}{l}\text { Fasciitis around, and } \\
\text { a slight increase in } \\
\text { the signal intensity of } \\
\text { the soleus muscle }\end{array}$ \\
\hline $\begin{array}{l}\text { Treatment for } \\
\text { myalgia }\end{array}$ & Steroids / none & $\begin{array}{l}\text { Steroids } \\
\text { (dramatic } \\
\text { response) }\end{array}$ & $\begin{array}{l}\text { Unresponive to } \\
\text { steroids } \\
\text { Tocilizumab }\end{array}$ & NSAID \\
\hline Recurrence & Under colchicine: None & None & $\begin{array}{c}\text { Under colchicine: Yes } \\
\text { Under tocilizumab: } \\
\text { None }\end{array}$ & $\begin{array}{c}\text { Under colchicine: Yes } \\
\text { Under canakinumab: } \\
\text { None }\end{array}$ \\
\hline $\begin{array}{l}\text { Number of } \\
\text { myalgia attacks }\end{array}$ & 3 & First attack & $\begin{array}{l}\text { Several undiagnosed } \\
\text { attacks for the last } 7 \\
\text { years }\end{array}$ & 4 \\
\hline $\begin{array}{l}\text { MEFV gene } \\
\text { mutation }\end{array}$ & M694V/V726A & $\begin{array}{l}\text { E148Q/ E148Q } \\
\text { P369S-R408Q }\end{array}$ & E148Q/- & M694V/M694V \\
\hline
\end{tabular}

F: female, M: male, ND: not done, NSAID: non sterodid antiinflamatuar drug.

and myalgia attacks for the last 7 years in her medical history without a specific diagnosis. She also had localized pain on her left thigh at admission. She had normal levels of CK and high levels of CRP as seen in PFMS. MRI of the lower limbs obtained several times for limb pain revealed high intensity of muscles and fascia appearing in different sites at each attack. Muscle biopsy obtained from quadriceps muscle revealed neutrophilic infiltration into the fascia and vascular endothelium of the fascia compatible with fasciitis. She responded well to colchicine and was diagnosed with FMF using the Tel-Hashomer criteria. Although this case has similarities with the previous one, myalgia has been considered as "spontaneous myalgia". The patient responded well to tocilizumab treatment in the follow up.

The first case was thought to have PFMS. However, it is usually seen symmetrically in extremities and is rarely controlled without steroids in the early period. In addition, muscle biopsies are usually normal in PFMS. ${ }^{8}$ The patient had a more localized pain in the right calf and fasciitis was established in the muscle 
biopsy. The findings of the second case with fasciitis was compatible with PFMS. The third case with a localized pain on left thigh was considered as spontaneous myalgia, however, she had fever and high levels of CRP, which are not expected in spontaneous myalgia. Our case also had a localized pain on calves at different periods and myalgia episodes lasted only for a few days and resolved without steroid prescription. None of the cases had a history of exercise and colchicine induced myalgia was excluded due to normal CK levels. It seems possible to gather all these patients with myalgia and FMF under one title, as FMF associated fasciitis. In addition, as the findings of patient two were compatible with PFMS, looking for fasciitis with MRI in further cases in the acute phase would elucidate whether it is characteristic for PFMS as seen in TRAPS.

FMF attacks more frequent than one per month despite the maximum tolerable doses of colchicine has been frequently used to define colchicine resistance. ${ }^{14}$ In such patients, antiIL-1 biologic agents are the first treatment of choice. ${ }^{14}$ Anakinra and canakinumab are the available anti-IL-1 agents in our country. We preferred canakinumab in our case and he had a complete response to febrile attacks and debilitating myalgia.

In conclusion, severe recurrent myalgia especially in calves or thighs, along with high levels of acute phase reactants and normal levels of CK in patients with FMF may emphasize a distinct form of myalgia marked by fasciitis, which does not require steroids. In such cases, MRI may be helpful and NSAIDs may be initially preferred before using steroids. Canakinumab may be useful for recurrent severe myalgia as well as frequent FMF attacks due to inadequate response to colchicine.

\section{REFERENCES}

1. Majeed HA. Differential diagnosis of fever of unknown origin in children. Curr Opin Rheumatol 2000; 12: 439-444.
2. Zemer D. Muscle pains in familial Mediterranean fever. Harefuah 1984; 106: 232-233.

3. Soylu A, Oztürk Y, Kasap B, Akman N, Türkmen M, Kavukçu S. Clinical quiz: a pediatric case presenting with fever and diffuse myalgia. Rheumatol Int 2005; 25: 314-316.

4. Fujikawa K, Migita K, Tsukada T, Kawakami A, Eguchi K. Protracted febrile myalgia syndrome in a Japanese patient with fasciitis detected on MRI. Intern Med 2014; 53: 2817-2819.

5. Hull KM, Wong K, Wood GM, Chu WS, Kastner DL. Monocytic fasciitis: a newly recognized clinical feature of tumor necrosis factor receptor dysfunction. Arthritis Rheum 2002; 46: 2189-2194.

6. Quillinan N, Mohammad A, Mannion G, et al. Imaging evidence for persistent subclinical fasciitis and arthritis in tumour necrosis factor receptorassociated periodic syndrome (TRAPS) between febrile attacks. Ann Rheum Dis 2010; 69: 1408-1409.

7. Otar Yener G, Ekici Tekin Z, Yuksel S. Psoriatic fasciitis in a pediatric patient: a case report. World J Clin Cases 2019; 7: 69-72.

8. Kaplan E, Mukamel M, Barash J, et al. Protracted febrile myalgia in children and young adults with familial mediterranean fever: analysis of 15 patients and suggested criteria for working diagnosis. Clin Exp Rheumatol 2007; 25(4 Suppl 45): S114-S117.

9. Abdel Halim MM, Al-Otaibi T, Donia F, et al. Protracted febrile myalgia syndrome in a kidney transplant recipient with familial mediterranean fever. Exp Clin Transplant 2015; 13: 188-192.

10. Schapira D, Ludatscher R, Nahir M, Lorber M, Scharf Y. Severe myalgia in familial mediterranean fever: clinical and ultrastructural aspects. Ann Rheum Dis 1988; 47: 80-83.

11. Mercan R, Turan A, Bitik B, Tufan A, Haznedaroglu $\mathrm{S}$, Goker B. Rapid resolution of protracted febrile myalgia syndrome with anakinra: report of two cases. Mod Rheumatol 2016; 26: 458-459.

12. Kotevoglu N, Sahin F, Ozkiris SO, Bankaoglu M, Sakiz D, Kuran B. Protracted febrile myalgia of familial mediterranean fever. Clin Exp Rheumatol 2004; 22(4 Suppl 34): S69-S70.

13. Umeda M, Aramaki T, Fujikawa K, et al. Tocilizumab is effective in a familial mediterranean fever patient complicated with histologically proven recurrent fasciitis and myositis. Int J Rheum Dis 2017; 20: 18681871.

14. Gül A. Approach to the patients with inadequate response to colchicine in familial mediterranean fever. Best Pract Res Clin Rheumatol 2016; 30: 296303. 